\title{
ABSTRACTS OF COMMUNICATIONS Proceedings of the Thirty-sixth Meeting of the Agricultural Research Modellers' Group
}

\author{
EDITED BY \\ J. FRANCE ${ }^{1}$ AND L. A. CROMPTON ${ }^{2}$ \\ ${ }^{1}$ Department of Animal \& Poultry Science, University of Guelph, Guelph, Ontario N1G 2W1, Canada \\ ${ }^{2}$ School of Agriculture, Policy and Development, The University of Reading, Whiteknights, PO Box 237, \\ Reading RG6 6AR, UK
}

This group, which is concerned with the applications of mathematics to agricultural science, was formed in 1970 and has since met at approximately yearly intervals in London for one-day meetings. The thirty-sixth meeting of the group, chaired by Dr T. R. Wheeler of The University of Reading, was held in the Kohn Centre at the Royal Society, 6 Carlton House Terrace, London on Friday, 26 March 2004 when the following papers were read.

Regional environmental benchmarks of arable farming. A. G. WILLIAMS ${ }^{1}$, D. L. SANDARS ${ }^{1}$, E. AUDSLEY ${ }^{1}$ AND K. W. T. GOULDING ${ }^{2}$. ${ }^{1}$ Silsoe Research Institute, Wrest Park, Silsoe, Bedford MK45 4HS, UK, ${ }^{2}$ Rothamsted Research, Harpenden, Hertfordshire AL5 2JQ, UK

A model to quantify the current and possible future environmental burdens of crop production systems in regions (NUTS 1) of England and Wales is presented. The model (MEASURES) calculates environmental burdens, profitability and crop outputs from arable and mixed farms using a systems approach on a whole farm scale. An environmental burden is a substance, such as nitrate, that causes an environmental impact. Farms are characterized by region using long-term mean rainfall, soil texture and slope (derived for $5 \mathrm{~km}$ grid squares) as inputs. Certain farm types were excluded from regions (e.g. no sugar beet in SW England) and particular grid squares were eliminated if they contained insufficient suitable land. Farm types included combinable arable, roots and arable, and arable with pigs, poultry or dairy cattle. Burdens from each farm type were calculated from the weighted means, according to the geospatial characteristics of each region.

The model broadly reproduces the cropping recorded in the Defra June Census. Wales, NE and NW England were eliminated as having insufficient arable activity. There was much similarity in the emissions of nitrate, ammonia, nitrous oxide and total denitrification as well as profitability between farms of the same types across the regions, but the SW tended to be more burdensome and less profitable than the others. This resulted mainly from the higher rainfall in the SW, which exacerbated nitrate leaching and soil erosion (SW is also the most sloping) and by lowering soil workability. Arable-only farms are, however, unusual in the SW, occurring in limited low rainfall areas, so caution is needed in interpretation.

Mixed farms were more burdensome than pure arable and pigs were worse than cattle or poultry when comparing using equal masses of excreted $\mathrm{N}$ on each farm type. Dairy farms were superficially the least profitable (without costing all overheads). One improved practice was evaluated and showed relatively little effect on nitrate, but a substantial change in soil erosion that was non-uniform across the regions.

The authors gratefully acknowledge the funding of this work by Defra.

Coexistence of fungicide resistant and sensitive strains under incomplete spray coverage. S. R. PARNELL $^{1,2}$, C. A. GILLIGAN ${ }^{2}$ AND F. VAN DEN BOSCH ${ }^{1} .{ }^{1}$ Biomathematics Unit, Rothamsted Research, Harpenden, Hertfordshire AL5 2JQ, UK, ${ }^{2}$ Epidemiology and Modelling Group, Department of Plant Sciences, University of Cambridge, Cambridge CB2 3EA, UK

Models of fungicide resistance often predict that the invasion of resistant strains into a fungicide treated 
pathosystem leads eventually to the complete exclusion of the sensitive strain (Kable \& Jeffrey 1980; Chin 1987; Gubbins \& Gilligan 1999). Empirical evidence illustrates that this is not always the case and that the coexistence of resistant and sensitive strains is possible over prolonged temporal periods (Fehrmann et al. 1982; Chin et al. 2001; Bierman et al. 2002). The factors influencing coexistence remain relatively unexplored. Coexistence, however, has important practical consequences: for example, the survival of the sensitive population under treatment, even at low levels, will enhance the post treatment recovery of sensitivity.

Fungicide spray application is imperfect and thus the target crop often receives incomplete coverage. This paper aims to show whether the heterogeneity introduced by incomplete spray coverage can facilitate the coexistence of sensitive and resistant strains. The model presented is an extension of the model by Gubbins \& Gilligan (1999), which described the development of fungicide resistance in a pathosystem under a homogeneous coverage of fungicide. We extend this model in two main ways. Firstly, we relax the assumption that complete spray coverage is always achieved and secondly, we explicitly model the spore dynamics within this heterogeneous system. The resulting model is a system of 6 linked differential equations. By analysing the competition between resistant and sensitive pathogen strains in a system characterized by the density dependent growth of treated and untreated host tissue, we identify thresholds for the invasion of fungicide resistant and sensitive pathogens and show that not only does incomplete spray coverage facilitate coexistence but also that the maximum density of healthy host tissue is achieved when there is coexistence of resistant and sensitive strains.

This work was funded by the BBSRC.

BIERMAN, S., FITT, B., VAN DEN BOSCH, F., BATEMAN, G. L., JENKYN, J. F. \& WELHAM, S. J. (2002). Changes in populations of Tapesia yallundae and Tapesia acuformis (eyespot) under different fungicide regimes in successive crops of winter wheat, 1984-2000. Plant Pathology 51, 191-201.

CHIN, K. (1987). A simple model of selection for fungicide resistance in plant pathogen populations. Phytopathology 77(5), 666-669.

CHIN, K., CHAVAILlAZ, D., KAESBOHRER, M., STAUB, T. \& FELSENSTEIN, F. G. (2001). Characterising resistance risk of Erysiphe graminis f.sp tritici to strobilurins. Crop Protection 20(2), 87-96.

FEHRMANN, H., HORSTEN, J. \& SIEBRASSE, G. (1982). Five years results from a long-term field experiment on carbendazim resistance of Pseudocercosporella herpotrichoides (Fron) Deighton. Crop Protection 1(2), 165-168.

GUBBINS, S. \& GILligAN, C. A. (1999). Invasion thresholds for fungicide resistance: deterministic and stochastic analyses. Proceedings of the Royal Society of London Series B 266, 2539-2549.

KABLE, P. \& JEFFREY, H. (1980). Selection for tolerance in organisms exposed to sprays of biocide mixtures: a theoretical model. Phytopathology 70, 8-12.

Calibration and sensitivity analysis of a model of the growing pig. D. M. GREEN AND C.T. WHITTEMORE. School of Geosciences, University of Edinburgh Agriculture Building, The King's Buildings, West Mains Road, Edinburgh EH9 3JG, $U K$

A mechanistic model of pig growth and nutrition, in terms of the retention of protein, lipid and live weight, was constructed with a view to its inclusion in an integrated management system for pig production (IMS) (Whittemore et al. 2001; Green \& Whittemore 2003). Initial model testing was by evaluation against a variety of independent data sets; however, model calibration and sensitivity analysis were considered a more beneficial and informative method of model evaluation.

Model parameter calibration using a revised Simplex algorithm was performed against data from pigs of three types ('meaty', 'lean', and 'fatty'). A number of key parameters of biological interest that had an empirical origin were calibrated: those for rates of tissue turnover, maintenance, and growth. After calibration, the estimates for these parameters were found to be close to those expected from experimental results. This would support both the use of such calibration in the testing of the model, and the methodology used in the construction and assembly of the model algorithms.

Sensitivity analysis of both the above and additional parameters indicated that the parameters could be divided into two groups: those controlling partitioning of nutrients into protein and lipid, and those controlling efficiency of nutrient conversion into biomass. For use in a real-time IMS system, model results suggest that a combination of the above classes of parameters can be used for model optimization.

The support of the sponsors: Defra Link SLP, MLC, BOCM PAULS Ltd, PIC Ltd, and Osborne Ltd is gratefully acknowledged.

GREEN, D. M. \& WHiTTEMORE, C. T. (2003). Architecture of a harmonised model of the growing pig for the determination of dietary net energy and protein requirements and of excretions into the environment (IMS Pig). Animal Science 77, 113-130.

WHITTEMORE, C. T., GREEN, D. M. \& SCHOFIELD, C. P. (2001). Nutrition management of growing pigs. In Integrated Management Systems for Livestock, BSAS Occasional Publication No. 28 (Eds C. M. Wathes, A. R. Frost, F. Gordon \& J. D. Wood), pp. 89-95. Penicuik: British Society for Animal Science. 
Simulating farmer decision making to predict future agricultural land use. E. AUDSLEY AND K. PEARNE. Mathematics \& Decision Systems Group, Silsoe Research Institute, Wrest Park, Silsoe, Bedford MK45 4HS, UK

This paper presents an approach to predicting the impact of future agricultural policies, socio-economic change and climate change on agriculture land use. The approach is based on individuals' decision making. Thus land use in any location results from farmers' decisions as they attempt to maximize their long-term profit, given the physical attributes of their land, most notably soil type, climate and slope. Slope determines whether mechanized arable cropping is feasible. Climate determines which crops will grow and mature. Soil type, with climate, determines how well a crop will grow and also determines limits on the winter time available for mechanized work. Crop simulation models predict the average crop yield over 30 years and its variability, but these models which are based on soil water models, do not include disease. A linear programming model (Annetts \& Audsley 2002) simulates a collection of farmers determining the cropping that maximizes profit margin over labour and machinery costs taking into account the soil workability. Because of the variability in yields and prices, each farmer, given the same information, processes it differently due to different perceptions, experiences and attitudes to risk. The model simulates this by randomly selecting yields and prices based on their historic variability. The outcome is thus a regional prediction of the cropping (Rounsevell et al. 2002). Examples of the results are given.

This research was funded by the Ministry of Agriculture, Fisheries and Food (now Defra), the EU Framework 5 program and the Biotechnology and Biological Sciences Research Council.

ANNETTS, J. E. \& AUDSLEY, E. (2002). Multiple objective linear programming for environmental farm planning. Journal of the Operational Research Society 53, 933-943.

ROUNSEVELL, M. D. A., ANNETTS, J. E., AUDSLEY, E., MAYR, T. \& REGISTER, I. (2002). Modelling the spatial distribution of agricultural land use at the regional scale. Agriculture, Ecosystems and Environment 95, 465-479.

The role of small-scale spatial interactions on the coexistence of rain forest species: using neighbourhood techniques and simulation models. C. J. BAMPFYLDE ${ }^{1,2}$, N. D. BROWN ${ }^{1}$, D. J. GAVAGHAN $^{3}$ AND P. K. MAINI ${ }^{2} .{ }^{1}$ Department of Plant Sciences, South Parks Road, Oxford OXI 3RB, UK, ${ }^{2}$ Mathematical Institute, 24-29 St. Giles', Oxford OX1 3LB, UK, ${ }^{3}$ Oxford University Computing Laboratory, Wolfson Building, Parks Road, Oxford $O X 13 Q D, U K$
Rain forests exhibit enormous tree species diversity, but the mechanisms for establishing and maintaining such diversity are intractable to observational or experimental studies. The aim of this mathematical modelling project is to try to identify the key mechanisms that permit long-term species co-existence.

We have shown previously that, without taking account of spatial interactions or temporal stochasticity (for example mast fruiting events observed in South East Asia), our models are unable to produce species coexistence (Bampfylde et al. 2004). We have developed a cellular automaton model that describes a spatially explicit stage-structured population. The model describes the population dynamics of different tree species, stratified into three stage classes or cohorts: seedlings; saplings; and adult trees. The model is mathematically intractable but we use simulations to investigate the dynamical behaviour of the model and investigate the life history strategy parameter space that allows for the tree species coexistence observed.

We highlight how statistical model reduction has compressed the number of effective species and how the forest dynamics recover or develop from a number of different management scenarios. Neighbourhood competition indices are also investigated and their statistical power in explaining an individual's growth is assessed.

A recent re-enumeration of permanent sample plots in Danum Valley, Sabah, Malaysia, provided an invaluable data set of seedling and sapling gap dynamics over 16 years. Evaluation of the model and parameter value estimation was carried out using these data.

The authors acknowledge the financial support of a research studentship from NERC for CJB and permission from the following to conduct research in Danum Valley: Yayasan Sabah, The Danum Valley Management Committee, Sabah Chief Minister's Department, and the Economic Planning Unit, Kuala Lumpur. We thank $\mathrm{Mr}$ Bahaman Ahmad (University of Malaysia Sabah) and $\mathrm{Mr}$ Tom Clements and Miss Lucy Moore for invaluable assistance in the field.

BAMPFYLDE, C. J., BROWN, N. D., GAVAGHAN, D. J. \& MAINI, P. K. (2004). Modelling rain forest dynamics: the role of competition. Ecological Modelling (submitted).

Modelling water pollution from livestock farming. M. B. McGECHAN AND C. F. E. TOPP. $R \& D$ Division, Scottish Agricultural College, West Mains Road, Edinburgh EH9 3JG, UK

Most water pollution takes the form of nutrients $(\mathrm{N}$ and $\mathrm{P}$ ) and pathogenic microorganisms excreted in faeces and urine being transported from the field to water bodies. Grazing animals deposit excreta in discrete concentrated patches (with known typical dimensions and $\mathrm{N}$ and $\mathrm{P}$ contents), whereas manure or slurry from housed animals is deposited fairly 
uniformly. Further non-uniformity arises during grazing because animals tend to congregate in certain areas of field for shelter, shade, or at feeders or drinking troughs.

Pollutant transport to water was simulated using adaptations of existing models. Soil $\mathrm{N}$ processes were represented by calibrations of the SOILN model, with interactive links to a grass growth model (McGechan \& Topp 2004). Rapid transport of solutes through macropores was represented by the 'two domain' MACRO model. An adaptation of MACRO was used to represent colloid transport processes for $\mathrm{P}$ and microorganisms, including trapping by straining and filtration, and sorption onto mobile colloids or static soil components (McGechan et al. 2002). Both SOILN and MACRO were adapted to represent deposition of faeces and urine in patches.

Results of simulations show that nitrate leaching can be reduced substantially by spreading manure or slurry in the spring when crops are actively extracting nitrogen from the soil. Where soil is very wet, macropore flow can lead to leaching of a high proportion of applied ammonium from urine (McGechan 2003a), as well as both particulate $\mathrm{P}$ and $E$. coli microorganisms from faeces (McGechan \& Vinten 2003), these losses arising within a few days after deposition. Slurry spreading on wet soil should therefore be avoided. Similar high levels of leaching arise during grazing on wet soil, indicating an environmental penalty from extending the grazing season into late autumn (McGechan 2003b). Due to non-linear relationships in the models, overall average leaching losses are substantially higher with animals congregating in certain areas of fields compared to grazing with a uniform stocking rate over the whole area.

This research was funded by SEERAD.

McGECHAN, M. B., JARVIS, N. J., HOODA, P. S. \& VINTEN, A. J. A. (2002). Parameterisation of the MACRO model to represent leaching of colloidally attached inorganic phosphorus following slurry spreading. Soil Use \& Management 18, 61-67.

MCGECHAN, M. B. (2003a). Modelling contamination of field drainage water by ammonium following slurry spreading. Biosystems Engineering 85, 111-120.

MCGECHAN, M. B. (2003b). Modelling phosphorus leaching to watercourses from extended autumn grazing by cattle. Grass and Forage Science 58, 151-159.

McGECHAN, M. B. \& VINTEN, A. J. A. (2003). Simulation of transport through soil of $E$. coli derived from livestock slurry using the MACRO model. Soil Use \& Management 19, 321-330.

McGECHAN, M. B. \& TOPP, C. F. E. (2004). Modelling environmental impacts of deposition of excreted nitrogen by grazing dairy cows. Agriculture, Ecosystems and Environment (in press).

Use of the NGAUGE DSS for analysis of options for compliance with NVZ legislation on UK dairy farms. A. DEL PRADO, L. BROWN AND D. SCHOLEFIELD. IGER, Soil Science and Environmental Quality, North Wyke Research Station, Okehampton, Devon EX20 2SB, UK

The purpose of this exercise was to study the scope for UK dairy farms under current fertilizer use to comply with the EU Nitrate directive by using alternative measures to those proposed by the NVZ action program for the UK. As a tool to obtain these results, the NGAUGE decision support system (DSS) was utilized. NGAUGE is a DSS that produces an optimal $\mathrm{N}$ fertiliser strategy, enabling the user to meet environmental and production targets in grasslands (Brown et al. 2000). The following measures were incorporated within the management of typical dairy farms under current fertilizer limits: (i) improving $\mathrm{N}$ fertilizer distribution by using the $\mathrm{N}$ fertilizer optimization routine of NGAUGE DSS, (ii) applying manure in March as opposed to February, (iii) farm yard manure instead of slurry and (iv) exporting manure to beef farming systems.

The results obtained from the implementation of these measures were compared to those results obtained in farms following the $\mathrm{NVZ}_{170}$ guidelines (only $170 \mathrm{~kg}$ organic $\mathrm{N} / \mathrm{ha} /$ year) in terms of herbage production and nitrate leaching losses. Our simulated results indicate that applying a single measure in some farms under current fertilizer practices may be as effective or even more effective than using the $\mathrm{NVZ}_{170}$ rules in reducing the $\mathrm{N}$ concentration in the leachate, with no penalty or even a boon in DM yield. Furthermore, when more than one abatement measure was introduced to farms, the ranges of improvement were wider. Exporting manure in conjunction with the former measures proved to result in bigger $\mathrm{N}$ leaching reductions compared to those under $\mathrm{NVZ}_{170}$ of up to $59 \%$ with an increase in herbage DM yield of up to $38 \%$.

Strategies of beef systems for manure importing enabled compliance with the EC nitrate directive on the dairy and beef farms, but increased leaching, as expected, on the beef farms.

This exercise demonstrated the ability of NGAUGE DSS to explore possible abatement measures as an alternative to the NVZ170 action program.

This research was funded by Defra.

BROWN, L., SCHOLEFIELD, D. \& JEWKES, E. (2000). A decision support system to optimise $\mathrm{N}$ use in grassland for economic and environmental targets. In Grassland Farming: Balancing Environmental and Economic Demands. Proceedings of the 18th General Meeting of the European Grassland Federation, Aalborg, Denmark, 22-25 May 2000 (Eds K. Soegaard, C. Ohlsson, J. Sehested, N. J. Hutchings \& T. Kristensen), pp. 458-460. Denmark: European Grassland Federation.

Dairy farms in central England under climate change in 2050: do they need to change? S. K. SHRESTHA, 
J. M. GIBBONS AND S. J. RAMSDEN. Division of Agricultural and Environmental Sciences, School of Biosciences, University of Nottingham, Sutton Bonnington Campus, Loughborough, Leicestershire LE12 5RD, UK

An increase in atmospheric temperature can affect dairy farms in two ways; first by decreasing production through heat stress suffered by individual animals and second by changing grass production, eventually affecting productivity of the farms. This study focuses on dairy farms in central England and considers the effects of climate change on grass production and conservation. It aims to determine whether these farms need to change under future climatic conditions and if so, what type of adaptations will be the best for maximizing their farm profits? A farm-level dynamic linear programme (FDLP) model was built in an attempt to answer these questions.

The FDLP model had six components; land, livestock, crops, milk, feeding system, and labour and machinery, and these components were constrained under stocking rate, milk quota, crop rotation, nutrient requirements for animals and field time available for farm operations. The objective function of the model was to maximize farm net margin within these constraints. The expected data for grass yield, crop yields and field time availability for central England in 2050 were taken from a previous study (Hossell et al. 2001). The model was run for the year 2000 (Base-run) with the farm level data and for 2050 (Climate-run) with expected grass yield, crop yields and available field time under climate change. The Base-run results were compared with the Climate-run results to see the effects of climate change on farms and any adaptation changes in farm activities in 2050. The FDLP model was run again (Adaptation-run) for 2050 with any changes in farm activities in the Climate-run restricted to the Base-run values. The difference in net margin between the Adaptation-run and the Climate-run, if negative, shows that farmers' need to change under future climatic conditions.

The results showed that the specialist dairy farms would not be affected much under future climate change. There was only a very small incentive $(<1 \%)$ for these farms to change. However, small farms would increase their net margin up to $5 \%$ if they adapt under climate change. The major change in farm activities was a shift from two-cut grass silage production to less labour intensive one-cut silage production. Although the increase in net margin was not very high, no extra cost was required to adopt this change and small farms can benefit most from it under climate change.

HOSSELL, J., RAMSDEN, S. J., HARRIS, D., GIBBONS, J. M., MATHEWS, A., CLARKE, J. \& POOLEY, J. (2001). Predicting the timescale of potential farm level responses and adaptations to climate change in England and Wales. MAFF project CC0333. Final Report.

The effect of soil structure on colonies of Rhizoctonia solani in soils at different bulk densities. T. D. HOLLINGSWORTH, A. J. STACEY, W. OTTEN AND C. A. GILligAN. Department of Plant Sciences, University of Cambridge, Cambridge CB2 3EA, UK

The spread of mycelia through soil is an important process in the transmission of infection between plants for many economically important plant pathogens. There is experimental evidence to suggest that manipulating the soil structure affects the spread of these mycelial fungi, such as Rhizoctonia solani (Otten \& Gilligan 1998; Otten et al. 1999; Otten et al. 2001; Harris et al. 2003), which may have implications for control strategies. A stochastic model of fungal growth through a pore-network, together with a three dimensional model of soil-pore structure, has been used to investigate the relationship between soil structure and fungal colony morphology.

Analysis of biological thin sections of soils, to which point sources of $R$. solani were introduced, showed that subsequent colony expansion was sparse at low bulk densities of soil, with denser colonies at high bulk densities (Harris et al. 2003). These two dimensional sections cannot indicate whether this shift in morphology is due to differences in pore size distributions at different bulk densities, changes in the three-dimensional connectivity of the pore-space, or, since the growth rate of the fungus may not be quantified from these samples, whether there is a change in the intrinsic growth patterns of the fungus.

In order to distinguish these hypotheses, three dimensional models for soil pore space and for fungal growth in a porous medium were constructed. The models show that at low bulk densities there are few, large pore spaces that have a small number of connections to other, distant, large pore spaces. This structure results in large, sparse fungal colonies. At high bulk densities, there are many smaller pore spaces which are connected to other, nearby, small pores, resulting in small, dense fungal colonies. At the highest bulk densities pores become isolated and the radius of the colonies is reduced accordingly. These qualitative results, which agree with those observed experimentally, can be seen for each of a range of simulated growth rates of the fungi. This suggests that the change in fungal colony morphology is a result of the structure of the pore space, rather than a shift in growth of the fungus.

This research was funded by the LSA Charitable Trust.

HARRIS, K., YOUNG, I. M., GILLIGAN, C. A., OTTEN, W. \& RITZ, K. (2003). Effect of bulk density on the spatial organisation of the fungus Rhizoctonia solani in soil. FEMS Microbial Ecology 44, 45-56. 
OTTEN, W. \& GILLIGAN, C. A. (1998). Effect of physical conditions on the spatial and temporal dynamics of the soil-borne fungal pathogen Rhizoctonia solani. New Phytologist 138, 629-637.

OtTEN, W., GILligAN, C. A., WATtS, C. W., DEXTER, A. R. \& HALL, D. (1999). Continuity of air-filled pores and invasion thresholds for a soil-borne fungal plant pathogen, Rhizoctonia solani. Soil Biology and Biochemistry 31, 1803-1810.

OTTEN, W., HALL, D., HARRIS, K., RITZ, K., YOUNG, I. M. \& GILLIGAN, C. A. (2001). Soil physics, fungal epidemiology and the spread of Rhizoctonia solani. New Phytologist 151, 459-468.

\section{Development of a stochastic genetic epidemiological model for gastro-intestinal nematode infection in sheep. M. NATH, J. A. WOOLLIAMS, R. PONG- WONG AND S. C. BISHOP. Roslin Institute, Roslin, Midlothian EH25 9PS, UK}

Gastro-intestinal parasites are a major problem in grazing livestock resulting in reduced animal performance and welfare along with increased costs associated with anthelmintic and management control measures. Genetic resistance to gastro-intestinal parasites in animals has been reported (Gasbarre $\&$ Miller 2000). Here we describe a stochastic geneticepidemiological model for gastro-intestinal nematode infection in sheep and present its applicability in predicting the responses to genetic selection strategies.

Briefly, the basic model framework is as follows. The epidemic is triggered by the ingestion of infective third-stage larvae $\left(\mathrm{L}_{3}\right)$ from pasture. Within the host system, the $\mathrm{L}_{3}$ transforms into $\mathrm{L}_{4}$ and $\mathrm{L}_{5}$ stages. The model combines all larval stages together and the number of larvae $(L)$ at $t$ th day is given by: $L_{t}=$ $L_{(t-1)}\left(1-\mu_{L}\right)+L_{i t}$, where $\mu_{L}$ is the host-induced larval mortality per day and $L_{i t}$ is the number of larvae ingested on the $t$ th day. The larvae finally establish as the adult parasites within the host body and the number of mature parasites $(M)$ at $t$ th day is represented by: $M_{t}=M_{(t-1)}\left(1-\mu_{M}\right)+L_{(t-j)}\left(1-\mu_{L}\right)^{(t-j)} E$, where $\mu_{M}$ is the host-induced mature parasite mortality per day, $j$ is the time taken by larvae to establish as mature parasites and $E$ is the establishment rate of larvae that transform into mature parasites. The female mature parasites lay eggs and the parameter fecundity $(F)$ represents the number of eggs laid per female worm per day. The above model framework captures the dynamics of the worm population. However, to introduce between-animal variation into the system, we assumed that host's genetic mechanisms regulate its parasite burden. Hence the model incorporates both major gene and polygenic inheritance for those parameters. Additionally, the parasite population may also be influenced by density dependent constraints, which are inverse functions of the worm population present within the host. Outside the host system (i.e. in pasture), the eggs are hatched to free-living first-stage larvae $\left(\mathrm{L}_{1}\right)$ that transform into $\mathrm{L}_{2}$ and $\mathrm{L}_{3}$. The parameters hatchability of eggs per day and larval mortality per day depend on weather conditions and hence may vary from time to time. The animal again takes up the $\mathrm{L}_{3}$ larvae from pasture and the whole cycle continues.

We have modelled the gastrointestinal parasite Teladorsagia circumcincta, which is a predominant nematode in sheep in the UK. An arbitrary initial pasture larval challenge was assumed, which declined over time and the number ingested by each animal was sampled from a normal distribution. The population of 1000 sheep formed the base population and by random mating five subsequent generations were generated. Each generation faced similar environmental conditions and initial natural challenge dose. The model was run for $180 \mathrm{~d}$. The outputs included larval burden $(L B)$, worm burden $(W B)$ and egg per $\mathrm{g}$ of faeces $(E P G)$ for each individual. An infinitesimal model was considered to describe host genetics with mean (and standard deviation) of parameters $\mu_{L}, E, \mu_{M}$ and $F$ as $0 \cdot 10(0 \cdot 01), 0 \cdot 6(0 \cdot 8)$, $0 \cdot 10(0 \cdot 01)$ and $100(72)$ and corresponding heritabilities as $0 \cdot 10,0 \cdot 30,0 \cdot 10$ and $0 \cdot 50$, respectively. The input parameters for $F$ were obtained from field data while others were adjusted such that model outputs for $L B, W B$ and $E P G$ mimicked the field observations. The model-generated individual data were used to estimate heritability $\left(\mathrm{h}^{2}\right)$, genetic $\left(\mathrm{r}_{\mathrm{G}}\right)$ and phenotypic $\left(\mathrm{r}_{\mathrm{P}}\right)$ correlation for different traits using residual maximum likelihood method by fitting an animal model considering the relationship among all individuals. A total of 1000 replications was run.

The estimates of mean and distribution of $L B$, $W B$ and $E P G$ matched closely with field data. The pooled estimates of $\mathrm{h}^{2}$ for $L B, W B$ and $E P G$ at $120 \mathrm{~d}$ were observed as $0 \cdot 16,0 \cdot 36$ and $0 \cdot 48$, respectively, indicating that realistic genetic control of these traits may be modelled. The estimates of $r_{G}$ and $r_{P}$ between $W B$ and $E P G$ were $0 \cdot 29$ and $0 \cdot 31$, whereas between $F$ and $E P G$ the estimates were 0.86 and $0 \cdot 77$, respectively. Although the variation in $E P G$ is influenced by variation in both $W B$ and $F$, the results suggest that at the genetic level, $F$ has a greater influence than $W B$. It was also observed that estimates of $\mathrm{r}_{\mathrm{G}}$ and $\mathrm{r}_{\mathrm{P}}$ between $E P G$ values at different time points almost remain unchanged. All estimates were in close agreement with experimental observations of gastro-intestinal nematode infection in sheep (Stear et al. 1997). In general, it may be concluded that the present model would be a valuable tool to investigate the consequences of genetic selection and infection status in animals under different scenarios.

The authors thank the Biotechnology and Biological Sciences Research Council for financial support. 
GASBARRE, L. C. \& MILLER, J. E. (2000). Genetics of helminth resistance. In Breeding for Disease Resistance in Farm Animals (Eds R. F. E. Axford, S. C. Bishop, F. W. Nicholas \& J. B. Owen), pp. 129-152. 2nd Edn. Oxford: CABI Publishing.

STEAR, M. J., BAIRDEN, K., DUNCAN, J. L., HOLMES, P. H., MCKELLAR, Q. A., PARK, M., STRAIN, S., MURRAY, M., BISHOP, S. C. \& GETTINBY, G. (1997). How hosts control worms. Nature 389, 27.

Modelling nitrogen fluxes at the landscape scale. M. R. THEOBALD $^{1}$, U. DRAGOSITS ${ }^{1,2}$, C. J. PLACE ${ }^{2}$, J. U. SMITH ${ }^{3}$, M. SOZANSKA ${ }^{3}$, L. BROWN ${ }^{4}$, D. SCHOLEFIELD ${ }^{4}$, A. DEL PRADO ${ }^{4}$, J. WEBB $^{5}$, P. G. WHITEHEAD ${ }^{6}$, A. ANGUS ${ }^{7}$, I. D. HODGE $^{7}$, D. FOWLER ${ }^{1}$ AND M. A. SUTTON ${ }^{1}$. ${ }^{1}$ Centre for Ecology \& Hydrology, Bush Estate, Penicuik, Midlothian EH26 OQB, UK, ${ }^{2}$ School of GeoSciences, University of Edinburgh, Drummond Street, Edinburgh EH8 9XP, UK, ${ }^{3}$ Department of Plant and Soil Science, University of Aberdeen, Cruickshank Building, St Machar Drive, Aberdeen AB24 3UU, UK, ${ }^{4} I G E R$, North Wyke Research Station, Okehampton, Devon EX20 2SB, UK, ${ }^{5}$ ADAS, Woodthorne, Wergs Road, Wolverhampton WV6 8TQ, UK, ${ }^{6}$ Department of Geography, The University of Reading, Reading RG6 6AB, UK, ${ }^{7}$ Department of Land Economy, University of Cambridge, 19 Silver Street, Cambridge CB3 9EP, UK

The distribution and impacts of different nitrogen pollutants are inextricably linked. To understand the problem fully, the interactions between the different pollutants need to be taken into account. This is particularly important when it comes to abatement techniques, since measures to reduce emissions of one nitrogen pollutant can often lead to an increase in another.

This project represents a step towards greater understanding of these issues by linking together new and existing nitrogen flux models into a larger framework to study the fluxes of ammonia, nitrous oxide, nitric oxide and nitrates. The existing models integrated into the framework are an arable field model (SUNDIAL), a grassland model (NGauge) and an atmospheric dispersion model (LADD), which have been modified to interact at a landscape scale via a common spatial database. A new model, FYNE (FarmYard Nitrogen Emissions), which simulates the emissions from livestock housing and animal waste storage has also been developed and incorporated into the framework. This modelling framework has been applied to simulate some of the nitrogen flows between fields, farms and the atmosphere within a UK study area for typical farm management scenarios.

The results of this study show that the impact of ammonia emissions can be quite localised whereas the effects of other pollutants such as nitrous oxide and nitrates will have impacts over greater distances. This work has highlighted the spatial variability of nitrogen fluxes and the need to study them over areas larger than the plot or field scale.

This research was funded under the Natural Environment Research Council's 'Global Nitrogen Enrichment' (GANE) programme (Grant No. NER/T/S/1999/00123).

\section{Individual based modelling of temporal and spatial slug} dynamics. Y. H. CHOI, D. A. BOHAN AND M. A. SEMENOV. Biomathematics Unit, Rothamsted Research, Harpenden, Hertfordshire AL5 2JQ, UK The slug, Deroceras reticulatum, is one of the most important pests of agricultural and horticultural crops in the UK and Europe. We have developed a spatially explicit, stochastic, individual based model (IbM) for D. reticulatum, which establishes a virtual arable field in which the spatial dynamics and density changes of the slug population may be simulated. This framework is a powerful tool across which small scale ecological research findings may be scaled-up to the population scale.

The full life cycle of D. reticulatum is implemented within the IbM, allowing us to trace the growth of individuals and to observe the density and spatial dynamics of the population and their impact on the virtual field ecosystem. State-dependent parameters were constructed using the environmental variables daily temperature and rainfall, and slug weight and geographical information. An extension to the daydegree concept was used to include rainfall within the parameters. In contrast to many population models, which use constant rates or rates dependent upon processes intrinsic to the population, the environmental dependency of the IbM parameters allows seasonality to be explicitly included in the modelling. Slug growth and dispersal were treated as stochastic, and statistical distributions estimated in laboratory and field were implemented to give the initial colonization densities and distributions within the virtual field. Two time delays for egg development and egglaying were included, as these were shown to be of great significance to how the slug population emerges from the winter.

The simulation results show, by evaluation against slug sample data, that the model describes well changes in slug numbers over a three year period. Moreover, the model could be used to describe slug population dynamics at different sites, by changing the initial density of slug eggs, but without changing the model structure. This suggested that rainfall and temperature are the parameters of overriding importance in determining slug population dynamics. A study of field heterogeneity indicated the importance of spatial structuring to slug population dynamics and the utility of the individual based model for simulating a range of potential spatial management treatments and habitat management strategies, such 
as "Push and Pull" (Smart et al. 2000), for slug control to maximize crop yield.

The field data came from a study funded by the Ministry of Agriculture, Fisheries and Food (now part of Defra) and Y.H.C. was funded through a grant from the Biotechnology and Biological Sciences Research Council of the United Kingdom.

SMART, L. E., PICKETT, J. A. \& POWELL, W. (1997). 'Push-Pull' strategies for pest control. Grain Legumes 15, $14-15$.

\section{A turgor maintenance hypothesis-based model for nitrate accumulation in glasshouse lettuce. $K$. ZHANG, I. G. BURNS AND M. K. TURNER. Nutrient and Pesticide Dynamics Team, Horticul- ture Research International, Wellesbourne, Warwick CV35 9EF, UK}

High nitrate concentration is often observed in glasshouse lettuce, especially under low light conditions when photosynthesis is restricted. Numerous experimental studies have been conducted to understand the underlying causes of nitrate accumulation in this crop. Although the role of nitrate in plants has now become clearer, modelling nitrate concentration in lettuce still remains a significant challenge due to the complexity of the issue.

In this study, a turgor maintenance hypothesisbased model (Seginer 2003; Zhang et al. 2004) is used to simulate nitrate concentration in lettuce during growth. It assumes that nitrate accumulates in the plant in response to a decline in soluble carbohydrates in order to contribute to the solute potential for leaf expansion. Additional features of the model include the simulation of soluble carbohydrates and internal water mass. The model divides non-structural biomass into two separate carbon pools instead of the single pool commonly used in plant growth simulation. The soluble carbohydrates pool receives carbon from photosynthesis when the assimilated carbon exceeds the amount needed for structural increment and growth and maintenance respiration. A water balance equation considering water uptake and transpiration is used to simulate time-dependent water mass stored in lettuce. Model simulations were compared with the measurements from hydroponically grown butterhead lettuce. Predictions of plant fresh weight/dry weight and soluble carbohydrate concentration were found to be in good agreement with the measurements, while nitrate concentration agreed better with measurement at the late plant development stages than the early stages.

This research is funded by Defra.

SEGINER, I. (2003). A dynamic model for nitrogen-stressed lettuce. Annals of Botany 91, 623-635.

ZHANG, K., BURNS, I. G., BROADLEY, M. R. \&

TURNER, M. K. (2004). Developing a dynamic model for glasshouse lettuce growth and nitrate concentration. Acta Horticulturae (in press).

Statistical modelling of pasture growth rates in a longterm trial. S. J. WELHAM ${ }^{1}$, B. R. CULLIS ${ }^{2}$, G. $\mathrm{LI}^{2}$ AND R. THOMPSON ${ }^{1} .{ }^{1}$ Rothamsted Research, Harpenden, Hertfordshire AL5 2JQ, UK, ${ }^{2} N S W$ Agriculture, Wagga Wagga Agricultural Institute, NSW 2650, Australia

The long-term agronomic trial, MASTER, was started in 1992 to develop and demonstrate a pasturecrop rotation system that was environmentally sustainable and economically viable on the acid soils of the traditional permanent pasture region in southeastern Australia. The experiment was described in detail by Li et al. (2001). The eight treatments consisted of permanent pasture systems and pasture-crop rotations, each with all combinations of annual or perennial pasture, with or without lime. The experiment was laid out as two blocks of 40 plots, with each block containing at least one plot in each phase of the pasture-crop rotations, and at least three plots for the permanent pasture systems. Plots under pasture were rotationally grazed by sheep with $17-18$ days grazing and 35 days between grazing. Stocking rates were adjusted to ensure plots were grazed back to a similar height. Pre- and post-grazing dry matter was taken over five years (February 1993 to February 1998).

The aim of this analysis was to assess differences in the rate of dry matter production during the pasture phases of the different systems, measured as the rate of dry matter production during the spell between grazing periods. Direct modelling of dry matter production across time was problematic due to heterogeneity, so an indirect approach was taken by modelling relative growth rates. The log-transformed dry matter measurements before and after grazing for each treatment were treated as separate curves that could be modelled in time using L-splines (Wahba 1990) within a mixed model framework, which also allowed for correlation between repeated measurements from individual plots. Estimates of dry matter production derived from the fitted curves showed good agreement with direct estimates and could be used to quantify differences in pasture accumulation between the different cropping systems.

We gratefully acknowledge funding from the Grains Research and Development Corporation of Australia.

LI, G. D., HELYAR, M. K., CONYERS, M. K., CULLIS, B. R., CREGAN, P. D., FISHER, R. P., CASTLEMAN, L. J. C., POILE, G. J., EVANS, C. M. \& BRAYSHER, B. (2001). Crop responses to lime in long-term pasturecrop rotations in a high rainfall area in southeastern Australia. Australian Journal of Agricultural Research 52, 329-341.

WAHBA, G. (1990). Splines for Observational Data. Philadelphia: SIAM. 